研 究

\title{
紫外線硬化樹脂を用いた磁性粉末の配向成形
}

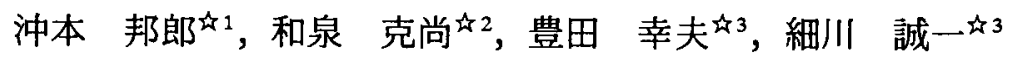 \\ 中1 摂南大学, ₹ 572-8508 寝屋川市池田中町 17-8. 捸南大学大学院工学研究科, ₹ 572-8508 寝屋川市池田中町 17-8.

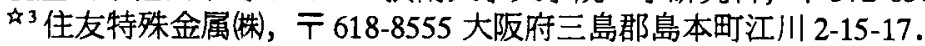

\section{Anisotropic Forming of Magnetic Powders Mixed with Ultraviolet Resin}

\author{
Kunio Okimoto ${ }^{\text {th }}$, Katsuhisa Izumi ${ }^{\text {tr }}$, Sachio Toyota ${ }^{43}$ and Seiichi Hosokawa ${ }^{43}$ \\ ${ }^{4}$ I Setsunan University, 17-8 Ikeda-nakamachi, Neyagawa 572-8508. ${ }^{2}$ Graduate School, Setsunan University, 17-8 Ikeda-nakamachi, \\ Neyagawa 572-8508. ${ }^{3}$ Sumitomo Special Metals Co. Ltd., 2-15-17 Egawa Simamoto-cho Mishima-gun, Osaka 618-8555.
}

Received September 17, 1998

\begin{abstract}
SYNOPSIS
For the purpose of solving the limitations such as shape and dimension for magnetic compact fabricated by conventional anisotropic forming under magnetic orienting field, the feasibility of a new magnetic forming process was studied. Ferrite powder mixed with UV resin was compacted in the die mold and followed by alignment under the magnetic field. Effects of viscosity of UV resin and forming condition on magnetic characteristics of the compact was investigated. Maximum degree of alignment for the ferrite powder reached to 0.826 . It was predicted that the proposed method had make it possible to fabricate a high performance magnet having the anisotropic alignment of the magnetic powder. The UV resin is desirable to have low viscosity, good properties such as formability and configuration stability for the compact and also parting- ability between the metal mold and the compact.
\end{abstract}

KEY WORDS

UV resin, orientation, alignment, anisotropic forming, ferrite, magnet, powder metallurgy

\section{1 緒言}

異方性磁石の成形では，通常，磁界配向プレス機が使用さ れている。これは周知の通り，磁界配向中に成形を行なう方 法1.2)である.この方法の場合，磁性体の配向度 $\mathrm{B}_{r} \mathrm{~J}$ ，は良好で あるが，磁極間に金型を配置するため，成形体の形状.寸法に 制約が多く，また生産性に問題がある。

そこで著者らは，これらの問題点の解消を目的として，慣 用のプレス機を用いて成形した後て磁界配向を行なう新しい 方法を提案する。具体的には紫外線 (以下, UV と呼称) 硬化 樹脂を用いる方法, 寒天バインダを用いる方法, MIMバイン ダを用いる方法などである。

本報告ではUV 硬化性と熱硬化性を有する樹脂を用いて， 磁性体の成形と磁界配向 (以後, 配向と略称)を別の工程で行 う方法の可能性について報告する．この場合，互いに相反す る性質である成形体の形状凍結性(保持性)と配向性をいかに して両立させるかが最大の検討課題である．そのため著者ら は「表面のみが硬く，内部は流動性を有する」という，いわ ば"生卵"のような状態の成形体をつくり出すことを目標とし た.その考え方の概念図をFig.1に示す.このような成形体は
表面が硬くて形状を保持しているが，内部は流動性があるの で配向が可能であると予想される，具体的なプロセスは，磁 性粉末をUV樹脂および熱硬化性樹脂と混練してから成形し， これにUVを照射して表面だけを固め，次に配向する。そし て配向後に加熱することにより成形体の内部まで固化させる. 配向度 $B_{r} / J$ 。などの磁気特性に及ぼすUV樹脂の粘度や成形条 件について調べた.なお，本研究においてはボンド磁石夕イ プのものを想定し，配向後の脱バインダと焼結は行わない。

\section{1 実験方法}

\section{2 高粘度のUV樹脂を用いた配向成形}

実験に使用した磁性粉末は，平均粒子径 $0.75 \mu \mathrm{m}$ (空気透過 法)の焼結磁石用ストロンチウム系フェライト粉末吕である。 バインダ用樹脂はアクリル/エポキシを主成分とした市販 [日 本ロックタイト侏製3016]のもので，UV樹脂と熱硬化性樹脂 が配合されたタイプである.樹脂の密度は $1.10 \mathrm{~g} \cdot \mathrm{cm}^{-3}$, 粘度 は $25^{\circ} \mathrm{C}$ の条件下で $5.50 \mathrm{~Pa} \cdot \mathrm{s}$ である.樹脂と磁性粉末の配合割 合は磁性粉末 80,85,90,95wt\% (樹脂 20,15,10,5wt\%)の 4 種 類で実験した。磁性粉末と樹脂の混練物を室温の下でプレス 
機によって縦 $12 \mathrm{~mm} \times$ 横 $12 \mathrm{~mm} \times$ 高さ $8 \sim 12 \mathrm{~mm}$ の直方体に金型 成形した. UV は出力 $1 \mathrm{~kW}$ の装置 (東芝電材侏製) で Fig.2の ように約 $200 \mathrm{~mm}$ の距離から成形体に照射した. 成形体の作製 パターンは次に示した A, B, Cの3 種類である。
A : 成形 $\rightarrow U V$ 照射により全体を硬化.
$B ：$ 成形 $\rightarrow$ 配向 $\rightarrow U V$ 照射により全体を硬化.
$C:$ 成形 $\rightarrow U V$ 照射により表面硬化 $\rightarrow$ 磁界配向 $\rightarrow U V$ 照射 により全体を硬化.

ここでパターンAは磁界配向を行わない従来からの金型成 形に相当する等方性永久磁石の製造方式，パターン $\mathrm{B}$ は提案 した新プロセスで成形後に磁界配向を行う方式であるが UV による配向前の表面硬化は行わない場合, パターンCはいわ ゆる"生卵"の状態の磁性体をつくり出すプロセスである。こ れらの詳細条件を Fig.3に示した.なお，UV照射には，本来 の表面硬化作用と間接的な温度上昇による加熱硬化作用があ る. 各パターンの最後の工程におけるUV照射は, 後者の成 形体内部を含めた試験片全体の加熱硬化用として用いたもの である。

\section{2 実騃結果と考察}

Table 1に成形体の密度と磁気特性の測定結果を示す. まず 成形体密度について述べる。磁性粉末の配合割合が $80 \mathrm{wt} \%$ 以

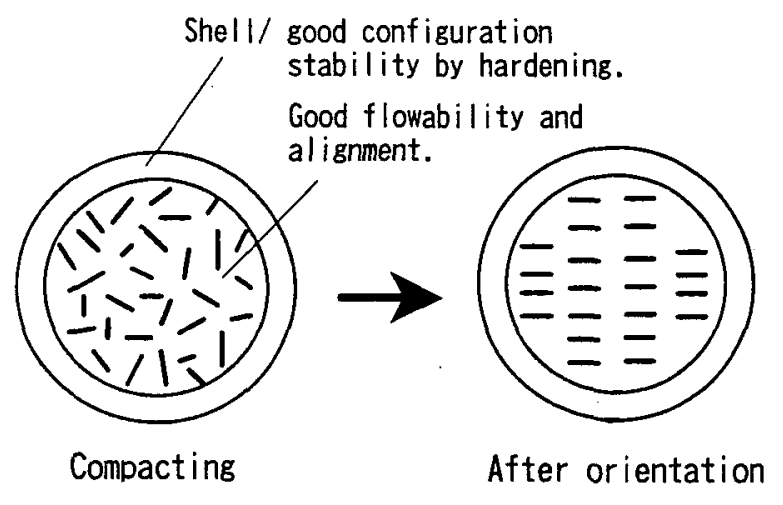

Fig.1 Conceptual illustration of proposed anisotropic forming.

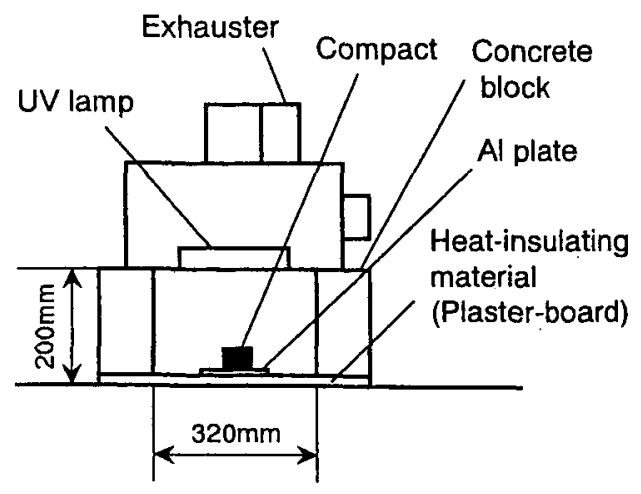

Fig.2 Outline of UV irradiation apparatus.
上では，配合割合が增えるにつれて密度が低下する傾向にあ る.これは,フェライトのような硬脆粉末(単味)で计高圧力 で成縮成形しても圧粉体密度は真密度の $65 \%\left(3.3 \mathrm{~g} \cdot \mathrm{cm}^{-3}\right)$ 程度 に過きず, 今の $10 \mathrm{MPa}$ の成形圧力では $2.5 \mathrm{~g} \cdot \mathrm{cm}^{-3}$ 3) であること に起因する．そのため，磁性粉末の配合割合が多くなるほど 成形体の気孔を埋めるために必要とされる UV 樹脂の不足が 顕著となり，成形体密度が低下する。

次に磁気特性であるが, 本研究では配向度 $\mathrm{B} / \mathrm{J}$, を評価基準 として用いた。 B/Jsの最大は配合割合が 80wt\%であるパター ンCのNo.5 試験片で，その値は 0.682 である。值そのものは 不十分であるが，他の成形条件に比べてNo.5が大きくなった 理由として，樹脂の割合が多いために配向時の流動性が良い こと，配向前のUV照射によって樹脂が加熱され粘度が低下 したことなどが考えられる.パターン BとCにおいて磁性粉 末が $80 \mathrm{wt} \%$ 以上で配向度 $\mathrm{B} / \mathrm{J}$, が低下する傾向を示すのは，配 向を促進するための樹脂の絶対量が不足するためである.ま た，パターン B,Cで作製した試験片には無配向のパターンA の試験片よりも配向度が高いものが多いので，本研究で行っ た方法により成形と配向を別々の工程で行える可能性がうか がえた. 以上の結果から, 更に高い $\mathrm{B}_{r} / J_{s}$ を得るためには粘度 の低い樹脂が適当と判断し，次の実験を行った.

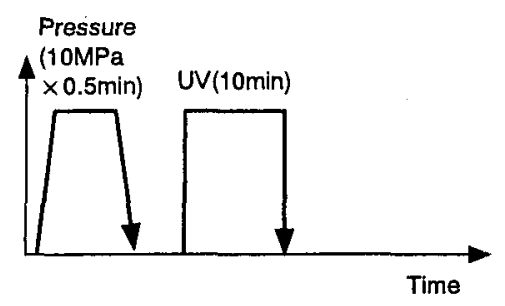

A : Conventional mold compacting method.

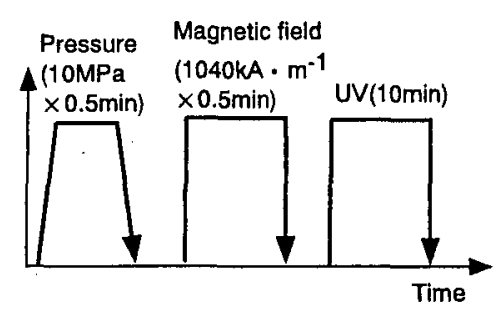

B : Proposed method with no UV irradiation before alignment of magnetic powder.

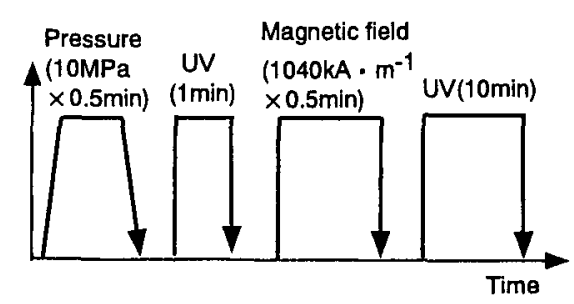

C : Proposed method with UV irradiation before alignment of magnetic powder.

Fig.3 Schematic illustration of forming processes using a high viscosity UV resin and the experimental conditions. 
Table 1 Magnetic characteristics of compacts obtained from forming patterns A, B and C.

\begin{tabular}{|c|c|c|cccccc|}
\hline Pattern & No. & $\begin{array}{c}\text { Powder } \\
\mathrm{wt} \%\end{array}$ & $\begin{array}{c}\text { Density } \\
\mathrm{g} \cdot \mathrm{cm}^{-3}\end{array}$ & $\begin{array}{c}\mathrm{J} s \\
\mathrm{~T}\end{array}$ & $\begin{array}{c}\mathrm{B} r \\
\mathrm{~T}\end{array}$ & $\begin{array}{c}(\mathrm{BH}) \max \\
\mathrm{kJ} \cdot \mathrm{m}^{-3}\end{array}$ & $\begin{array}{c}\mathrm{H} \mathrm{J}^{\mathrm{I}} \\
\mathrm{kA} \cdot \mathrm{m}^{-1}\end{array}$ & $\mathrm{Br} / \mathrm{J} s$ \\
\hline $\mathrm{A}$ & 1 & 80 & 3.88 & 0.150 & 0.088 & 1.3 & 119.0 & 0.587 \\
$\mathrm{~A}$ & 2 & 95 & 3.73 & 0.182 & 0.111 & 2.1 & 115.4 & 0.610 \\
\hline $\mathrm{B}$ & 3 & 80 & 3.92 & 0.161 & 0.105 & 1.9 & 122.7 & 0.652 \\
$\mathrm{~B}$ & 4 & 95 & 3.75 & 0.175 & 0.107 & 1.9 & 115.4 & 0.611 \\
\hline $\mathrm{C}$ & 5 & 80 & 3.99 & 0.157 & 0.107 & 2.0 & 122.3 & 0.682 \\
$\mathrm{C}$ & 6 & 85 & 4.15 & 0.173 & 0.104 & 1.8 & 118.5 & 0.601 \\
$\mathrm{C}$ & 7 & 90 & 4.02 & 0.175 & 0.107 & 1.9 & 116.6 & 0.611 \\
$\mathrm{C}$ & 8 & 95 & 3.29 & 0.178 & 0.105 & 1.9 & 116.7 & 0.590 \\
\hline
\end{tabular}

3

\section{低粘度のUV 樹脂を用いた配向成形}

3.1 実験方法

次に 1.04Pas $\left(25^{\circ} \mathrm{C}\right)$ の粘度が小さい樹脂を用いて2.1 と同じ

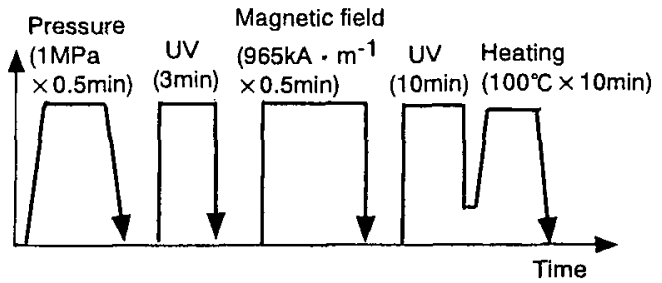

$D$ : Proposed method with UV irradiation before alignment of magnetic powder. (Magnetic powder $=80,85 \mathrm{wt} \%$ )

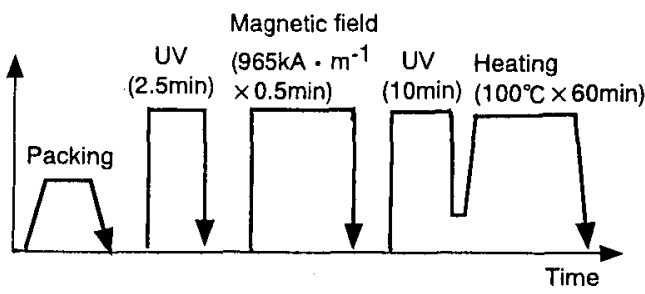

E : Proposed method with UV irradiation before alignment of magnetic powder. (Magnetic powder $=40,45,50,55 w t \%$ )

Fig.4 Schematic illustration of forming processes using a low viscosity UV resin and the experimental conditions.
ような実験を行ったここの樹脂は変性アクリレ一ト系の一液 性樹脂で，密度は $1.07 \mathrm{~g} \cdot \mathrm{cm}^{-3}$ である。磁性粉末はボンド磁石 用のストロンチウム・フェライト系粉末を使用した．樹脂と 磁性粉末の配合割合は磁性粉末 40, 45, 50, 55, 80, 85wt\% (樹 脂 $60,55,50,45,20,15 \mathrm{wt} \%$ )の 6 種類で実験した. 成形バ夕一 ンは以下のD，Eのようである。実験条件の詳細はFig.4の通り である。

\section{$\mathrm{D}:$ 成形 $\rightarrow U V$ 照射 $\rightarrow$ 配向 $\rightarrow U V$ 照射＆熱湯での加熱によ り全体を硬化。 \\ $\mathrm{E}$ : ポリエチレン容器に充填成形 $\rightarrow U V$ 照射 $\rightarrow$ 配向 $\rightarrow U V$ 照射 \&電気炉での加熱により全体を硬化.}

これらは前述の"生卵"の状態の磁性体を作り出す方式に相 当する.なお，パ夕ーン Eの場合，磁性粉末が $40 \sim 55 \mathrm{wt} \%$ と 少ないため混錬物の流動性が大きすぎ金型成形が困難である ため,プラスチック製容器に混練物を流し込んで無加圧成形 したものである．またUVを照射しただけでは熱硬化が十分 でなかったため，最後に更に加熱して完全に熱硬化させた。 3.2 実験結果と考察

密度と磁気特性の測定結果を Table 2に示す. 磁性粉末の配 合割合が $40 \sim 55 \mathrm{w} \%$ \% 時の成形体密度は, 配合割合が多くな るにつれて増大し，複合材料における混合則がほぼ成立する。 密度に関する混合則は約 80wt\%の状態で成立しなくなり，そ れ以上ではTable 1で述べたように密度は逆に低下する.成形

Table 2 Magnetic characteristics of compacts obtained from forming patterns D and E.

\begin{tabular}{|c|c|c|c|c|c|c|c|c|}
\hline Pattern & No. & $\begin{array}{r}\text { Powder } \\
\text { wt } \%\end{array}$ & $\begin{array}{l}\text { Density } \\
\mathrm{g}^{\cdot} \mathrm{cm}^{-3}\end{array}$ & $\begin{array}{l}\text { Js } \\
\mathrm{T}\end{array}$ & $\begin{array}{c}\mathrm{B} r \\
\mathrm{~T} \\
\end{array}$ & $\begin{array}{l}(\mathrm{BH}) \max \\
\mathrm{kJ} \cdot \mathrm{m}^{-3}\end{array}$ & $\begin{array}{c}\mathrm{H} c J \\
\mathrm{kA} \cdot \mathrm{m}^{-1}\end{array}$ & $\mathrm{Br} / \mathrm{J} s$ \\
\hline D & 1 & 80 & 3.03 & 0.195 & 0.161 & 4.9 & 295.3 & 0.826 \\
\hline D & 2 & 85 & 3.36 & 0.219 & 0.166 & 5.0 & 291.1 & 0.758 \\
\hline E & 3 & 40 & 1.38 & 0.047 & 0.041 & 0.4 & 306.9 & 0.873 \\
\hline E & 4 & 45 & 1.22 & 0.046 & 0.042 & 0.4 & 308.5 & 0.927 \\
\hline$E$ & 5 & 50 & 1.45 & 0.057 & 0.051 & 0.5 & 304.8 & 0.886 \\
\hline$E$ & 6 & 55 & 1.96 & 0.099 & 0.091 & 1.6 & 306.3 & 0.910 \\
\hline
\end{tabular}


体密度がピークを有する約 $80 \mathrm{wt} \%$ の近傍は，配向を促進させ るための UV 樹脂の最適配合割合の状態と関連があるように 思われる．この点に関しては今後の検討課題としたい.

次に磁気特性について述へる。磁性粉末 $80,85 \mathrm{wt} \%$ のパー ンDの試験片の $\mathrm{B}_{/} / \mathrm{J}_{s}$ はそれぞれ 0.826 と $0.758 て ゙ ， 2$ の実験の 場合よりも向上した. パターンEの 40〜 55wt\%の場合は 0.873 〜0.927とかなり高いB/J。を示したが, 磁性粉末が少ないため に， $B_{r} J_{s}$ 以外の磁気特性が劣る. また，この配合割合は実用 的な点からはほとんど意味を持たないと思われる。

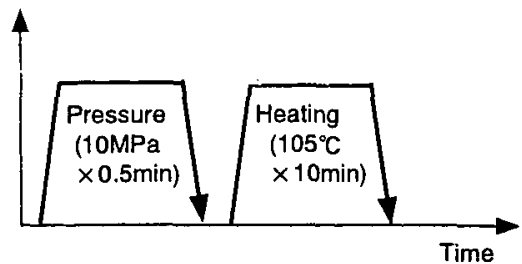

F : Conventional mold compacting method.

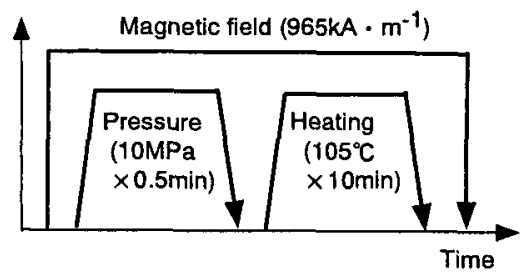

$G$ : Conventional orientation forming under magnetic field.

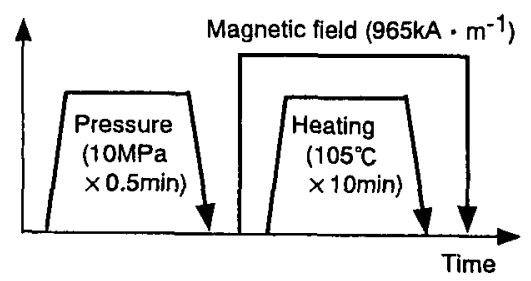

$H$ : Proposed method with no UV irradiation before alignment of magnetic powder.

Fig.5 Schematic illustration of experimental procedures for the test in which the specimen is not taken out of the mold.
ここまでの実験を通じて，磁性粉末とUV樹脂の混鍊時に おいて䚓汼を激しく行うとUV樹脂に気泡が発生して成形体 に気孔が生じる問題や，成形体を金型から取り出す際の離型 性か悪いなどの問題があった.そこで次に，金型から成形体 を取り出さずに配向を行う方法を試みた。

\section{4 金型から取り出さない状態での配向成形}

\section{1 実験方法}

この実験に用いた磁性粉末および樹脂は 3.1 と同じものであ る. 樹脂と磁性粉末の配合割合付磁性粉末 $85,90,95 \mathrm{wt} \%$ (樹 脂 $15,10,5 \mathrm{wt} \%)$ の 種類で実験した。成形バターンは以下の 通りで，その詳細条件を Fig.5に示した.
$\mathrm{F}:$ 成形 $\rightarrow$ 金型内で加熱.
$G ：$ 磁界 ON $\rightarrow$ 成形 $\rightarrow$ 金型内で加熱 $\rightarrow$ 磁界 OFF.
$\mathrm{H}:$ 成形 $\rightarrow$ 磁界 ON $\rightarrow$ 金型内で加熱 $\rightarrow$ 磁界 OFF.

ここでパターンFは従来からの金型成形法に順ずる場合， $G$ は成形と配向を同時に行う慣用の磁界中配向成形法, $\mathrm{H}$ は成 形後に配向を行う本研究で提案した方法である.これらの実 験では金型から成形体を取り出さずに配向したため,UV照射 は行わなかった。試験片の熱硬化は金型をヒーターで加熱し て行った。

\section{2 実験結果と考察}

Table 3 は密度と磁気特性の測定結果である。慣用の磁界中 成形法であるパターン $\mathrm{G}$ の配向度は 0.80 以上であったが, パ ターンHの成形と配向を別々に行う新方式の場合は $0.68 \sim 0.80$ である。一方，従来からの金型成形法に相当する $\mathrm{F}$ の場合の $\mathrm{B}_{N} \mathrm{~J}_{s}$ は 0.64〜0.70である. 原理的には，提案した方式による 配向度 $\mathrm{B}_{r} / \mathrm{J}_{\mathrm{J}}$ の值が慣用の磁界配向プレス機を用いた場合の $\mathrm{B}_{r} /$ $J_{s}$ を上回ることは考えられないが，磁性体の成形と配向を別 工程で行ってもある程度の $\mathrm{B}_{r} / \mathrm{J}$ sが得られることが判明した。

また，これまでの検討により，良好な成形条件とは配向度 $\mathrm{B}_{r} \mathrm{~J}_{s}$ を維持し，かつ成形体と金型との離型性のよい条件であ ることが分かった。そこで，今後は配向度 $\mathrm{B} / \mathrm{J}$, ，成形体の強 度や流動性との関係を明らかにすることにより，適切な成形

Table 3 Magnetic characteristics of compacts obtained from forming patterns $F, G$ and $\mathrm{H}$.

\begin{tabular}{|l|c|c|cccccc|}
\hline Pattern & No. & $\begin{array}{c}\text { Powder } \\
\text { wt \% }\end{array}$ & $\begin{array}{c}\text { Density } \\
\mathrm{g} \cdot \mathrm{cm}^{-3}\end{array}$ & $\begin{array}{c}\mathrm{J} s \\
\mathrm{~T}\end{array}$ & $\begin{array}{c}\mathrm{B} r \\
\mathrm{~T}\end{array}$ & $\begin{array}{c}(\mathrm{BH}) \max \\
\mathrm{kJ} \cdot \mathrm{m}^{-3}\end{array}$ & $\begin{array}{c}\mathrm{HcJ} \\
\mathrm{kA} \cdot \mathrm{m}^{-1}\end{array}$ & $\mathrm{Br} / \mathrm{Js}$ \\
\hline $\mathrm{F}$ & 1 & 85 & 3.34 & 0.208 & 0.136 & 3.3 & 279.1 & 0.654 \\
$\mathrm{~F}$ & 2 & 90 & 3.26 & 0.236 & 0.150 & 4.0 & 282.7 & 0.636 \\
$\mathrm{~F}$ & 3 & 95 & 3.08 & 0.215 & 0.150 & 4.0 & 276.7 & 0.698 \\
\hline $\mathrm{G}$ & 4 & 85 & 3.41 & 0.245 & 0.219 & 9.0 & 293.5 & 0.894 \\
$\mathrm{G}$ & 5 & 90 & 3.21 & 0.235 & 0.191 & 6.7 & 288.6 & 0.813 \\
$\mathrm{G}$ & 6 & 95 & 3.05 & 0.222 & 0.189 & 6.7 & 284.1 & 0.851 \\
\hline $\mathrm{H}$ & 7 & 85 & 3.38 & 0.230 & 0.183 & 6.1 & 294.3 & 0.796 \\
$\mathrm{H}$ & 8 & 90 & 3.34 & 0.226 & 0.154 & 4.2 & 284.3 & 0.681 \\
$\mathrm{H}$ & 9 & 95 & 3.11 & 0.216 & 0.152 & 4.1 & 278.3 & 0.704 \\
\hline
\end{tabular}


条件を探索すると同時に，粉末潤滑材などを添加して配向度 $\mathrm{B}_{r} / \mathrm{J}_{s}$ を改善するための方法について更に検討を加えたいと 思っている.

\section{5 結言}

慣用の磁界配向プレス機を用いた成形法には，成形体の形 状・寸法などに関する制約がある。これを解消することを目 的として,UV樹脂とストロンチウム系フェライト粉末との混 練物を用いて，成形した後で磁界配向する新しいプロセスを 試みた。得られた結果は以下の通りである。

(1) 提案した方法によって磁性体の配向を行うことが可能であ ると判断された。

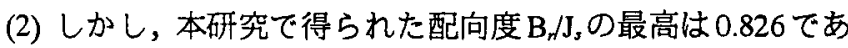
り，十分に満足できる值とは言えない，BdJsを更に向上さ せるためには，今後，UV樹脂の配合割合や成形温度など の条件の適正化を図る必要がある。
(3) 本研究用の樹脂としては粘性が小さく, 配向性・形状保持 性が優れ，かつ離型性が良好で気泡発生の少ないものが望 ましい.

最後に，実験に協力していたたいた摂南大学工学部機械工 学科の 1997 年度卒業研究学生 (当時) 中西亮太君, 1998 年度 卒業研究学生 高岡優君に感謝の意を表する.

\section{文献}

1）岸本芳久,山下 治: "非水系バインダーによるスプレー造 粒粉を用いたNd-Fe-B磁石の磁気特性",粉体および粉末冶 金, 45(1998)373-378.

2）高橋涉，小原公一，石垣尚幸: "Nd-Fe-B 系磁石粉末の RIP 成形挙動 ", 粉体および粉末治金, 45(1998)176-181.

3）沖本邦郎，和泉克尚，佐藤富雄，豊田幸夫, 細川誠一："燒 結接合法によるフェライト部品の作製", 粉体および粉末治 金, 45(1998)763-768. 